\title{
Critical Success Factors for Implementing Supply Chain Management Systems - The Perspective of Selected German Enterprises
}

Full Paper

\author{
Christian Leyh \\ Technische Universität Dresden, \\ Chair of Information Systems, esp. IS in \\ Manufacturing and Commerce, \\ Helmholtzstr. 10, 01069 Dresden, Germany \\ Email: Christian.Leyh@tu-dresden.de
}

\author{
Julia Thomschke \\ Technische Universität Dresden, \\ Chair of Information Systems, esp. IS in \\ Manufacturing and Commerce, \\ Helmholtzstr. 10, 01069 Dresden, Germany
}

\begin{abstract}
The aim of our study was to provide a contribution to the research field of critical success factors (CSFs) with a focus on SCM system implementations. Therefore, we conducted a systematic literature review in order to identify CSFs for those projects. On the basis of that review, we conducted interviews within German large-scale enterprises and with consultants experienced with SCM system implementations. As a result, we showed that all the factors found in the literature also affected the success of SCM projects in the studied companies. Additionally, we were able to identify six further CSFs with the interview study. However, within those SCM projects, technological factors gained more importance compared to those factors which influence the success of ERP projects the most. For SCM projects, factors like Data migration, as well as SCM system tests, are even more important than Top management support or Project management, which are the most important factors for ERP projects.
\end{abstract}

\section{INTRODUCTION}

$\mathrm{T}$ oday's enterprises are faced with the globalization of markets and rapid changes in the economy. In order to cope with these conditions, the use of technology, as well as information and communication systems, is almost mandatory. Specifically, the adoption of enterprise resource planning (ERP) systems as standardized systems that encompass the activities of an entire enterprise has become an important factor for today's businesses. The demand for ERP applications has increased for several reasons, including competitive pressure to become low-cost producers, expectations of revenue growth, and the desire to re-engineer businesses to respond to market challenges. A properly selected and implemented ERP system offers several benefits, such as considerable reductions in inventory costs, raw material costs, lead time for customers, production time, and production costs [1]-[4]. Therefore, the majority of enterprises around the world use ERP systems.

However, using ERP systems to optimize "the inside conditions" of an enterprise still may not be sufficient to be competitive in today's business environment. In the last decade and continuing through today, the logistics of an enterprise are strongly influenced by changing business conditions. These conditions have changed dramatically in recent years - e.g., customers expect that companies will respond quickly to their needs and wishes and that these companies will also be very flexible. In addition, the customers more frequently are requiring widely different product variants. In addition to this required variety, there is also a trend towards increasing collaboration with a variety of suppliers and the inclusion of a wide variety of distribution channels, mostly on an international level, caused by increasing globalization. To cope with these requirements, the optimization of enterprises and their processes has to extend beyond the companies' borders; therefore, information systems have to be able to cross these borders, too. Here, the focus lies on optimal planning, management and control of the material, and information flow across the entire value chain [5]. Confronted with these issues, ERP systems are often reaching their functional limits.

One approach to dealing with the needs for joint planning of production and logistics activities across enterprise borders is the supply chain management (SCM) concept. To provide the needed relevant information for adequate planning and calculations and to support the exchange of information between supply chain partners, information systems are essential components within the SCM concept [6]-[8]. As supply chain-wide information systems, SCM systems are becoming increasingly important for enterprises. The increasing importance of SCM systems is also emphasized by the fact that many companies have already implemented such systems, or at least plan to implement these systems in the near future. Therefore, the use of and the need for adequate SCM systems has increased in recent years [9].

However, the implementation of an information system (e.g., an ERP system or an SCM system) is a complex and time-consuming project during which companies face great opportunities, but at the same time also face enormous risks. To take advantage of the potential opportunities rather than get caught by the risks of these implementation projects, it is essential to focus on those factors that support the successful implementation of an information system [10], [11]. By 
being aware of these factors, a company can positively influence the success of their implementation project and effectively minimize the project's risks [10]. Recalling these so-called critical success factors (CSFs) is of high importance whenever a new information system is to be adopted and implemented or a running system needs to be upgraded or replaced. Errors during the selection, implementation, or maintenance of information systems, wrong implementation approaches, or systems that do not fit the requirements of the enterprise can all cause financial disadvantages or disasters, perhaps even leading to insolvency. E.g., when considering ERP implementation projects, several examples of negative scenarios can be found in the literature (e.g., [12], [13]). Here, SCM implementation projects can result in an even more complex project structure since the companies face not only enormous internal challenges but many external challenges as well.

However, literature dealing with SCM projects and their critical success factors can only rarely be found, whereas CSFs of ERP projects have already been considered in numerous scientific publications. Several case studies, surveys, and literature reviews on CSFs of ERP projects have been conducted by different researchers (e.g., [4], [14][17]).

Hence, considering the increasing importance of the use of SCM systems, the aim of our study was to focus on the implementation of SCM systems, focusing in particular on the differences in CSFs of ERP projects and SCM system implementations. Therefore, we conducted a systematic literature review in order to identify CSFs for SCM projects and to update the existing reviews of CSFs. On the basis of the CSFs we identified, we conducted multiple interviews within German enterprises which have already implemented an SCM system, as well as with consultants from SCM manufacturers with specific experience in SCM projects, in order to obtain insights into the similarities and differences among CSFs for SCM system implementations. Overall, our study was driven by the following research questions:

Q1: What are the critical success factors of SCM system implementations?

Q2: What similarities and differences exist between critical success factors for ERP implementation projects and SCM implementation projects?

Therefore, the paper is structured as follows. The next section deals with the results of our literature review. We will point out which factors are most important and which factors seem to have little influence on the success of an SCM implementation project. Next, our data collection methodology is described before the results of the interviews are presented and discussed and the research questions are answered. Finally, the paper concludes with a summary of the results and discusses the limitations of our study.

\section{II.LITERATURE REVIEW OF CRITICAL SUCCESS FACTORS FOR SCM PROJECTS}

A critical success factor is defined according to [15] as any condition or element that is seen as necessary in order for the system implementation to be successful. As mentioned in the introduction, in order to identify factors that affect the success or failure of ERP projects, several case studies, surveys, and literature reviews have already been conducted by a number of researchers (e.g., [15], [16], [18]). However, most of the literature reviews cannot be reproduced, because descriptions of the review methods and procedures are lacking. Some researchers have pointed out the limitations of the currently available literature review articles, specifically noting that they lack methodological rigor [19]. Therefore, in order to gain insight into the field of CSFs for SCM projects, we conducted a literature review by systematically reviewing articles in five different databases, as well as papers drawn from several international conference proceedings. The literature review to identify the CSFs was performed in several steps, similar to the approach suggested by [20]. Here, we adapted an approach which we have previously used to update the existing CSF frameworks for ERP projects (see [17], [21]).

The steps of our review procedure are presented below. An overview is given in Figure 1 with regard to the numbers of papers identified or remaining during/after each step. With each step, the number of papers was reduced according to the assembly of different criteria.

Step 1 \& Step 2: The first two steps were to define the sources for the literature review and the search terms for the database-driven review. Therefore, several databases and conference proceedings were first identified. Keywords selected for this search were mostly derived and adapted from the keywords we used for our systematic review of the ERP CSF literature [17], [21]. To make our review reproducible, we have listed the databases and search terms in Table 1.

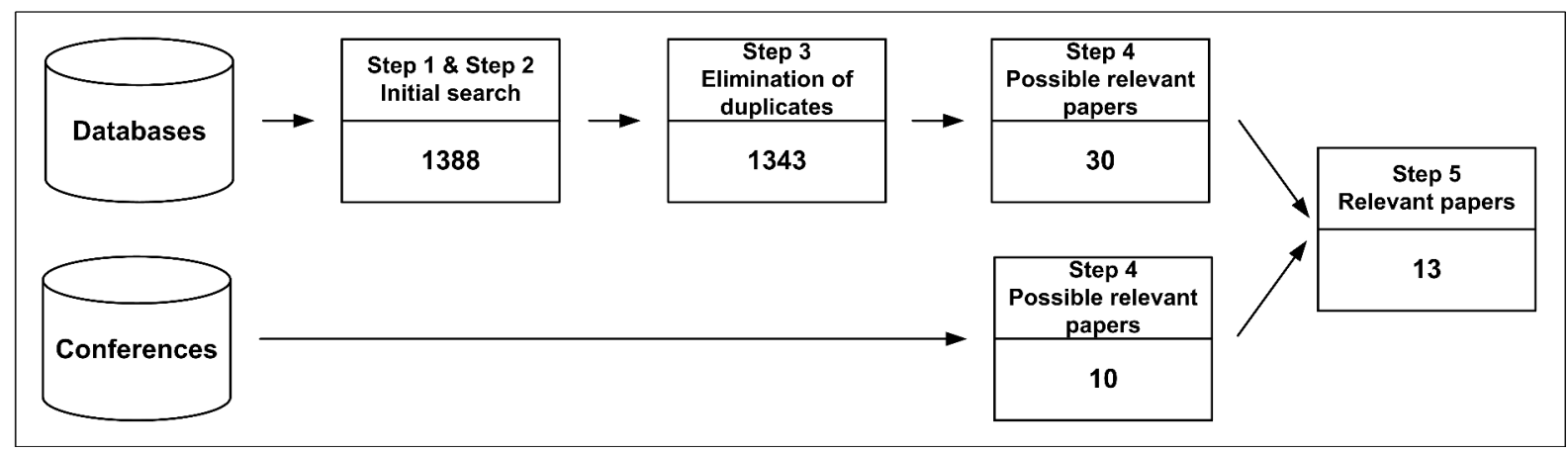

Figure 1. Progress of the literature review 
TABLE 1. SEARCH FIELDS AND SEARCH TERMS FOR THE DATABASE-DRIVEN REVIEW

\begin{tabular}{|c|c|c|}
\hline $\begin{array}{c}\text { Database + Search } \\
\text { fields }\end{array}$ & Se & terms / / Kerrwo \\
\hline $\begin{array}{l}\text { Academics Search } \\
\text { Complete: } \\
\text { "TI Title" OR “AB Abstract } \\
\text { or Author supplied } \\
\text { abstract" }\end{array}$ & \multirow{5}{*}{$\begin{array}{l}\text { SCM + system + success* } \\
\text { SCM + system + fail* } \\
\text { SCM + system + crit* } \\
\text { SCM + system + fact* } \\
\text { SCM + system + csf } \\
\text { SCM + system + cff } \\
\\
\text { APS + system + success* } \\
\text { APS + system + fail* } \\
\text { APS + system + crit* } \\
\text { APS + system + fact* } \\
\text { APS + system + csf } \\
\text { APS + system + cff }\end{array}$} & \multirow{5}{*}{$\begin{array}{l}\text { supply chain management + system + } \\
\text { success* } \\
\text { supply chain management + system + fail* } \\
\text { supply chain management + system + crit* } \\
\text { supply chain management + system + fact* } \\
\text { supply chain management + system + csf } \\
\text { supply chain management + system + cff } \\
\text { advanced planning and scheduling + system } \\
+ \text { success* } \\
\text { advanced planning and scheduling + system } \\
+ \text { fail* } \\
\text { advanced planning and scheduling }+ \text { system } \\
+ \text { crit* } \\
\text { advanced planning and scheduling }+ \text { system } \\
+ \text { fact* } \\
\text { advanced planning and scheduling + system } \\
+ \text { csf } \\
\text { advanced planning and scheduling + system } \\
+ \text { cff }\end{array}$} \\
\hline $\begin{array}{l}\text { Business Source } \\
\text { Complete: } \\
\text { "TI Title" OR "AB Abstract } \\
\text { or Author supplied } \\
\text { abstract" }\end{array}$ & & \\
\hline $\begin{array}{l}\text { Science Direct: } \\
\text { "Abstract, Title, } \\
\text { Keywords" }\end{array}$ & & \\
\hline $\begin{array}{l}\text { SpringerLink: } \\
\text { "Title" OR “Abstract" }\end{array}$ & & \\
\hline $\begin{array}{l}\text { WISO: } \\
\text { "General search field" }\end{array}$ & & \\
\hline
\end{tabular}

Since the WISO database also provides German papers, we used the German translation of most of the search terms as well. For the conferences, only inappropriate search fields and search functionality were provided.

Hence, we decided to review the abstracts and titles of the conference papers in this step manually. We used the proceedings of four conferences:

- International Conference on Information Systems (ICIS)

- Americas Conference on Information Systems (AMCIS)

- European Conference on Information Systems (ECIS)

- Wirtschaftsinformatik (WI)

Step 3: During step 3 we performed the initial search according to step 1 and step 2, and afterwards eliminated duplicate results. The initial search provided 1,388 papers from the databases. After eliminating the duplicates, 1,343 articles remained. From the conference search, 10 papers remained. Altogether, 1,353 papers were identified during the initial search step.

Step 4: Step 4 included the identification of irrelevant papers. During the initial search, we did not apply any restrictions. The search was not limited to the research field of IS; therefore, papers from other research fields were also included in the results. Thus, these irrelevant papers had to be excluded. Additionally, the majority of SCM papers focused on the implementation of the supply chain management concepts itself without dealing with information systems. Therefore, these papers had to be excluded as well. The identification of these irrelevant papers was done by reviewing the abstracts of the papers and, if necessary, by looking into the paper's content. Of the 1,353 papers, only 30 stemming from the database search remained, along with all 10 conference papers. Together, this yielded a total of 40 papers that were potentially relevant to the field of CSFs for SCM system implementations (see Figure 1).

Step 5: The fifth and final step consisted of a detailed analysis of the remaining 40 papers and the identification of the CSFs. Therefore, the content of all papers was reviewed in depth for the purpose of categorizing the identified success factors. Emphasis was placed not only on the wording of these factors, but also on their meaning. After this step, only 13 relevant papers that suggested, discussed or mentioned CSFs of SCM projects remained. In five of these 13 papers, CSFs of SCM projects were directly focused on within the conducted investigation, whereas in the other eight papers CSFs were discussed but these factors 
were not explicitly investigated with empirical studies. For each paper, the CSFs were captured along with the publication year, the type of data collection used, and the companies (e.g., the number and size) from which the CSFs were derived.

All 13 papers were published between 2000 and 2012 . Table 2 shows the distribution of the papers by publication year. As is shown, there are not many papers published per year that deal with CSFs of SCM system implementation projects.

TABLE 2. PAPER Distribution By YeAR

\begin{tabular}{|c|c|c|c|}
\hline Year & Papers & Year & Papers \\
\hline 2012 & 1 & 2005 & 1 \\
\hline 2011 & & 2004 & 2 \\
\hline 2010 & & 2003 & \\
\hline 2009 & 3 & 2002 & \\
\hline 2008 & 1 & 2001 & \\
\hline 2007 & & 2000 & 2 \\
\hline 2006 & 3 & & \\
\hline
\end{tabular}

Overall, 22 factors influencing the success of SCM system implementations could be identified within the literature review. Table 3 shows the results of our review, i.e., the CSFs identified, ordered by each factor's total number of occurrences in the reviewed papers.
The factors Top management support and involvement, Compatibility of the SCM system, and Data migration / data accuracy are the three most-named factors, with each being mentioned in seven articles.

However, the differences in the CSF frequencies are only minimal and are related to the small number of identified papers. Therefore, to derive CSFs that are important for SCM implementation projects and to realize their different levels of importance is difficult due to the small number of studies focusing solely on these CSFs. Here, the minimal focus paid to SCM system implementations can be clearly seen as a research gap in the SCM system research field. To gain a deeper insight into this research field and to identify further factors not mentioned in the small number of articles, we set up an empirical study focusing on CSFs of SCM system implementations. We investigated these CSFs in depth by interviewing experienced SCM consultants as well as enterprises that have already implemented SCM systems. The results of this interview study will be part of the following sections.

Due to space constraints, detailed descriptions and definitions for each identified factor cannot be given within this article, but will be provided by the first author upon request.

TABLE 3. SCM PROJECT CSFS IN RANK ORDER BASED ON

FREQUENCY OF APPEARANCE IN ANALYZED LITERATURE

\begin{tabular}{|c|c|c|c|}
\hline Critical Success Factor & $\begin{array}{c}\text { Number of } \\
\text { papers }\end{array}$ & Critical Success Factor & $\begin{array}{c}\text { Number of } \\
\text { papers }\end{array}$ \\
\hline $\begin{array}{c}\text { Top management support and } \\
\text { involvement }\end{array}$ & 7 & Available resources & 3 \\
\hline $\begin{array}{c}\text { Compatibility of the SCM system } \\
\text { (with other information systems and } \\
\text { the IT infrastructure) }\end{array}$ & 7 & (Organizational) Fit of the SCM & 3 \\
\hline $\begin{array}{c}\text { Data migration / data accuracy } \\
\text { User training }\end{array}$ & 7 & Involvement of end-users and & 3 \\
\hline stakeholders & External consultants & 3 \\
\hline Balanced project team & 6 & SCM system tests & 2 \\
\hline Project management & 5 & SCM system acceptance / resistance & 2 \\
\hline Change management & 4 & Environment and organizational & culture \\
\hline Clear goals and objectives & 4 & Project team leadership & 2 \\
\hline Company's strategy / strategy fit & 3 & Use of a steering committee & 1 \\
\hline Cooperation with supply chain & 3 & Skills, knowledge, and expertise & 1 \\
\hline partners & 3 & Vendor relationship and support & 1 \\
\hline
\end{tabular}




\section{INTERVIEW STUDY - CRITICAL SUCCESS FACTORS FOR SCM IMPLEMENTATION PROJECTS}

\section{Study Design - Data Collection Methodology}

To gain an empirical insight into SCM implementation projects and to gain an understanding of the CSFs for those projects, we used a qualitative exploratory approach within German large-scale enterprises and within German SCM system manufacturers. We chose to focus on German companies due to our cultural background.

The units of analysis in our study are the implementation projects carried out within the enterprises, as well as the SCM projects that the consultants have performed thus far in their careers. For the data collection, we conducted several interviews with members of the SCM implementation project teams and with consultants from German SCM system manufacturers in order to identify the factors that they determined to be relevant for the success of the projects.

During this process, we interviewed employees from nine large-scale enterprises located in Germany. The companies operate in different industry sectors and have implemented different SCM systems. Table 4 gives an overview of the companies and the interviewees. Within these enterprises, different SCM systems have been implemented (which cannot be named directly within this paper for data protection reasons).

TABLE 4. OVERVIEW OF THE LARGE-SCALE ENTERPRISES AND INTERVIEWEES

(Number of EMPLOYEes ARE CATEGORIZED DUE TO DATA PROTECTION)

\begin{tabular}{|c|l|c|l|}
\hline Company & \multicolumn{1}{|c|}{ Industry sector } & Number of employees & \multicolumn{1}{|c|}{ Interviewee } \\
\hline C 1 & Automotive industry & $1,000-5,000$ & Head of the IT department \\
\hline C 2 & $\begin{array}{l}\text { Manufacturing of metal } \\
\text { goods / Machine-building } \\
\text { industry }\end{array}$ & $100-500$ & $\begin{array}{l}\text { Head of the materials } \\
\text { management department }\end{array}$ \\
\hline C 3 & Automotive industry & $1,000-5,000$ & $\begin{array}{l}\text { Head of the company } \\
\text { organization department }\end{array}$ \\
\hline C 4 & Consumer goods industry & $>15,000$ & Project leader of the SCM project \\
\hline C 5 & Automotive industry & $1,000-5,000$ & $\begin{array}{l}\text { Head of the accounting and IT } \\
\text { department }\end{array}$ \\
\hline C 6 & $\begin{array}{l}\text { Building services } \\
\text { engineering }\end{array}$ & $>15,000$ & Business unit manager for SCM \\
\hline C 7 & Construction industry & $>20,000$ & $\begin{array}{l}\text { Head of the materials } \\
\text { management and IT departments }\end{array}$ \\
\hline C 8 & Construction industry & $1,000-5,000$ & Project manager for logistics \\
\hline C 9 & Electronics industry & $\begin{array}{l}\text { Business unit manager for supply } \\
\text { chain innovations }\end{array}$ \\
\hline
\end{tabular}

Four companies have implemented the same SCM system; all the other companies have implemented different systems - some quite small and industry-specific systems and some more widespread systems on the SCM market. Most of the implementation projects took place in the mid2000s. All of the interviewees were somehow directly involved in their respective companies' SCM system implementation projects.

In order to gather and include the SCM system manufacturers' perspectives in our study, we focused on information system manufacturers, with a specific emphasis on SCM implementations. Here, we interviewed three consultants from three different SCM manufacturers. Among the SCM consultants, we were able to interview consultants with longtime experience in several implementation projects.

To gain a deep and detailed view of the enterprises and their structures as well as of the consultants' experiences, we chose semi-structured interviews as our method of data collection. The interviews were conducted in retrospect 
regarding the SCM projects between July and October 2013. The interviews were designed as partially standardized interviews using open to semi-open questions as initial starting points for the conversation. Both personal (face-toface) interviews and telephone interviews were conducted by the authors. An interview guideline was developed, based on the questions of [22], who conducted a similar study within the field of ERP implementation projects, and also on the basis of one of our previous CSF studies (in the field of ERP projects), which focused on smaller companies and their experiences in ERP implementations [21]. We changed the questions to align with our identified CSFs (see Table 3) to ensure that all of the factors were discussed in the interviews. The interview guideline consisted of more than 30 main questions with further sub-questions that referred to the identified CSFs. These questions were formulated in an open way, so that it would be possible to identify "new" CSFs from the interviews that were not identified in the literature review. This questionnaire was sent to interviewees prior to the interviews to allow them to prepare for their interviews. The complete listing of the formulated questions and their assignment to the success factors is not included in this paper, but will be provided by the first author upon request.

For a better analysis of the results, we recorded all of the interviews (the interviews typically took between 60 and 90 minutes) and transcribed them afterwards. As a first step, non-verbal and para-linguistic elements and other elements that were not relevant to the study were excluded. Next, in order to evaluate the CSFs, the interviews were analyzed with reference to each CSF question block. We matched the answers and statements of the interviewees to the respective factors. Therefore, we had to formulate respective coding rules. Afterwards, each CSF was ranked according to a three-tier scale (2-very important factor; 1-medium important factor; 0-less/non-important factor) and, for a finer classification, according to a five-tier scale (4-very important factor; 3-important factor; 2-factor was seen as relevant; 1 -factor was mentioned but not seen as being very relevant; 0-factor was not seen as relevant or important/factor was not mentioned at all). This rating was done regarding the respective statements of the interviewees. We used these two scales to gain a preliminary understanding of whether differences would occur by using a finer/more detailed scale. Here, the five-tier-scale could be seen as more appropriate for determining the different levels of importance for the factors. After setting up this ranking of CSFs, we discussed the factor rating with other researchers in this field to reduce the subjectivity of the rating. Finally, this procedure resulted in a ranking of the CSFs according to the interviewees' statements and answers.

\section{Results of the Interviews}

For each interview, a ranking of the critical success factors was set up by the authors. A final ranking was created including all interviews and all individual rankings (see Table 5). As shown, the top three most important factors for SCM system implementation projects according to our study are Change management, Data migration / data accuracy, SCM system tests and Available resources with around or above 35 out of possible 48 points. Each of the 22 factors stemming from the literature review was mentioned by at least one interviewee.

Additionally, six further factors (Organizational structure, Business process reengineering, Troubleshooting, Knowledge management, Project champion and Vendor's tools and implementation methods) could also be identified during the interviews. These factors are printed in bold in Table 5.

However, four of these additional factors seem to have less influence on the success of SCM implementation projects, since they are ranked as 20 or lower. Only Organizational structure and Business process reengineering - with nearly or above 30 out of 48 possible points - seem to have at least a medium influence on the SCM project success.

To categorize critical success factors, [18] suggest a matrix scheme. Here, they consider the tactical or strategic direction of the CSFs and divide them into organizational and technological factors [18]. Thus, tactical CSFs relate instead to short-term aspects and goals of the system implementation project itself, whereas strategic factors aim at the long-term impacts of activities with strong connections to the development of the organization in relation to the mission, vision and core competencies of the business activity. Considering the technological and organizational character of the CSFs, the specificity and significance of technological factors are strongly dependent on the SCM systems themselves, whereas organizational factors focus on corporate culture and its environment with its specific processes and structures [18], [23], [24]. Table 6 gives an overview of the categorization of the top twelve of the identified CSFs in our study with a focus on their ranking. 
TABle 5. CSFs ACCORding to the FIVE-TIER-SCALE RATING

\begin{tabular}{|c|c|c|c|c|c|}
\hline Rank & Factor & $\begin{array}{c}\text { Factor } \\
\text { rating } \\
\text { (five-tier- } \\
\text { scale) } \\
\end{array}$ & Rank & Factor & $\begin{array}{l}\text { Factor } \\
\text { rating (five- } \\
\text { tier-scale) }\end{array}$ \\
\hline 1 & Change management & 38 & \multirow{4}{*}{15} & Project team leadership & 27 \\
\hline 2 & $\begin{array}{l}\text { Data migration / data } \\
\text { accuracy }\end{array}$ & 36 & & $\begin{array}{l}\text { Vendor relationship and } \\
\text { support }\end{array}$ & 27 \\
\hline \multirow[b]{2}{*}{3} & SCM system tests & 35 & & Communication & 27 \\
\hline & Available resources & 35 & & $\begin{array}{l}\text { Compatibility of the SCM } \\
\text { system (with other information } \\
\text { systems and the IT } \\
\text { infrastructure) }\end{array}$ & 27 \\
\hline \multirow{2}{*}{5} & $\begin{array}{l}\text { Top management support } \\
\text { and involvement }\end{array}$ & 32 & 19 & $\begin{array}{l}\text { Company's strategy / strategy } \\
\text { fit }\end{array}$ & 26 \\
\hline & $\begin{array}{l}\text { SCM system acceptance / } \\
\text { resistance }\end{array}$ & 32 & 20 & Troubleshooting & 25 \\
\hline \multirow{5}{*}{7} & User training & 31 & \multirow{2}{*}{21} & Knowledge management & 24 \\
\hline & Project management & 31 & & $\begin{array}{l}\text { Environment and } \\
\text { organizational culture }\end{array}$ & 24 \\
\hline & $\begin{array}{l}\text { Skills, knowledge, and } \\
\text { expertise }\end{array}$ & 31 & 23 & $\begin{array}{l}\text { Involvement of end-users and } \\
\text { stakeholders }\end{array}$ & 19 \\
\hline & Clear goals and objectives & 31 & 24 & $\begin{array}{l}\text { Cooperation with supply chain } \\
\text { partners }\end{array}$ & 18 \\
\hline & Organizational structure & 31 & 25 & External consultants & 17 \\
\hline 12 & Balanced project team & 30 & \multirow{2}{*}{26} & Use of a steering committee & 14 \\
\hline \multirow{2}{*}{13} & $\begin{array}{l}\text { (Organizational) Fit of the } \\
\text { SCM system }\end{array}$ & 28 & & Project champion & 14 \\
\hline & $\begin{array}{l}\text { Business process } \\
\text { reengineering }\end{array}$ & 28 & 28 & $\begin{array}{l}\text { Vendor's tools and } \\
\text { implementation methods }\end{array}$ & 7 \\
\hline $\begin{array}{l}4-\mathrm{ve} \\
\text { seen } \\
\max \end{array}$ & $\begin{array}{l}\text { portant factor; } 3 \text {-importa } \\
\text { ing very relevant; } 0 \text {-factc } \\
\text { possible rating on the ba }\end{array}$ & $2-1$ & $\begin{array}{l}\text { S se } \\
\text { evan }\end{array}$ & $\begin{array}{l}\text { as relevant; } 1 \text {-factor was me } \\
\text { r important/factor was not me }\end{array}$ & $\begin{array}{l}\text { but not } \\
\text { d at all) / }\end{array}$ \\
\hline
\end{tabular}

We oriented around the classification and categorization of the factors according to [23], [24]. The factors of the top three are highlighted. It is shown that only a few CSFs (2 out of the top 12) are technological factors, whereas more than $50 \%$ of the factors ( 7 out of the top 12) are organizational factors with a strategic characteristic. However, the top 12 factors are spread out among all four categories, although most of them are part of the organizational category. Remarkably, two of the most important factors are part of the technological view. 
TABle 6. Categorization of CSFs (Model AdAPted From [18], [23], [24])

\begin{tabular}{|c|c|c|c|c|}
\hline & \multicolumn{2}{|l|}{ Strategic } & \multicolumn{2}{|l|}{ Tactical } \\
\hline \multirow{8}{*}{ 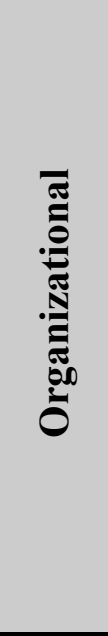 } & Critical Success Factors & Rank & Critical Success Factors & Rank \\
\hline & Change management & 1 & User training & 7 \\
\hline & Available resources & 3 & Skills, knowledge and expertise & 7 \\
\hline & $\begin{array}{l}\text { Top management support and } \\
\text { involvement }\end{array}$ & 5 & Project management & 7 \\
\hline & SCM system acceptance / resistance & 5 & & \\
\hline & Clear goals and objectives & 7 & & \\
\hline & Organizational structure & 7 & & \\
\hline & Balanced project team & 12 & & \\
\hline อ ฮี & & & Data migration / data accuracy & 2 \\
\hline$\Leftrightarrow$ & & & SCM system tests & 3 \\
\hline
\end{tabular}

\section{DISCUSSION}

Regarding these factors, the interviewees mostly acknowledge the descriptions of how the factors are summarized in the literature.

By looking at the rankings of the literature review, both at the ranking of the interview study and as a comparison at the ranking of an ERP CSF literature review from a former investigation (see [21]), the differences become obvious. Table 7 shows the respective top five factors.

As it is shown, the factor Top management support and involvement is always part of the top 5 factors. In both literature reviews this factor is the most important factor for the projects' success. Also, Change management is seen as a very important factor both for ERP projects and for SCM projects (as it is mentioned as the most important factor within the interview study). However, for SCM projects, technological factors (e.g., Data migration / data accuracy and SCM system tests) also seem to have a larger influence on the projects than they have on ERP projects. At least these factors are not ranked very high in the literature review for ERP implementations (see [21]).

An additional comparison of the results from the literature analysis and the interview study shows that the interviewees named and described twelve out of the 28 CSFs as they are described and defined in the literature, whether for SCM implementations or for ERP implementations. These factors are:
- Business process reengineering

- Knowledge management

- Change management

- Organizational structure

- Company's strategy / strategy fit

- Project management

- Compatibility of the SCM system

- Project team leadership

- Data migration / data accuracy

- SCM system tests

- Environment and organizational culture

- User training

Regarding the 16 other factors that are discussed by the interviewees in the way other than how they are described and defined in the literature, we cannot discuss the differences of all 16 factors at this point. However, we will point out these differences for some example factors:

- Top management support and involvement: The support of the top management was not seen as helpful by all interviewees. Some of them even mentioned that this had a negative influence on the project. For these interviewees, a lower level of top management support and less involvement from the managers were seen as beneficial since this would avoid long decision-making processes and other complications. 
TABLE 7. COMPARISON OF THE TOP Five FACtors

\begin{tabular}{|c|c|c|c|}
\hline Rank & $\begin{array}{c}\text { Results of the SCM } \\
\text { projects' literature review } \\
\text { (13 papers) }\end{array}$ & $\begin{array}{c}\text { Results of the ERP projects' } \\
\text { literature review (320 } \\
\text { papers) }\end{array}$ & Results of our interview study \\
\hline \multirow{3}{*}{1} & $\begin{array}{l}\text { Top management support } \\
\text { and involvement }\end{array}$ & \multirow{3}{*}{$\begin{array}{l}\text { Top management support and } \\
\text { involvement }\end{array}$} & \multirow{3}{*}{ Change management } \\
\hline & $\begin{array}{l}\text { Compatibility of the SCM } \\
\text { system }\end{array}$ & & \\
\hline & $\begin{array}{l}\text { Data migration / data } \\
\text { accuracy }\end{array}$ & & \\
\hline 2 & & Project management & Data migration / data accuracy \\
\hline \multirow{2}{*}{3} & & \multirow{2}{*}{ User training } & Available resources \\
\hline & & & SCM system tests \\
\hline 4 & User Training & Change management & \\
\hline \multirow[b]{2}{*}{5} & \multirow[b]{2}{*}{ Balanced project team } & \multirow[b]{2}{*}{ Balanced project team } & $\begin{array}{l}\text { Top management support and } \\
\text { involvement }\end{array}$ \\
\hline & & & $\begin{array}{l}\text { SCM system acceptance / } \\
\text { resistance }\end{array}$ \\
\hline
\end{tabular}

- Balanced project team: According to the literature for this CSF, project teams should consist of fixed and variable project members. However, such project team compositions were only used in two of the interviewed companies. The majority of the enterprises tended to use fixed project teams without variable members. Furthermore, in considering the literature, a high level of experience for the project team members in the field of software implementations is also an important aspect for the project team. However, this was not confirmed by interviewees. Mostly, the project members were not very experienced in this field.

- Skills, knowledge, and expertise: In the literature, experience, training and personal capabilities, skills and knowledge are all seen as positive impact factors on the project's success and can help to avoid errors and mistakes during the various project phases, or at least can lead to fast reactions. In the studied enterprises, the users' skills and knowledge (especially with regard to SCM systems or other software implementation projects) were described as really low. But this lack of experience and knowledge did not have any apparent negative impact on the projects' success.

- Use of a steering committee / Troubleshooting: Clear differences are also shown with respect to the use of a steering committee. According to the literature, it is almost essential to use a steering committee to manage and to supervise the implementation projects. However, only a few companies in our study had at least established some kind of a steering committee. Most of them did not see the necessity for a steering committee. In addition, the project plans of the companies contained no predefined troubleshooting plans or actions, which are seen as a mandatory aspect for software implementations according to the literature.

- Communication: As stated in the literature, in order to have adequate communication within the project teams, within the company itself and among SCM cooperation partners during the entire SCM system implementation, the development of a specific and detailed communication strategy is important. Yet, in the interviewed enterprises communication was done, for example, on a regular basis via meetings or telephone conferences. However, an explicit 
and specific communication strategy was developed only for one implementation project. Considering the communication, some interviewees also mentioned that it is sometimes easier just to inform the management rather than getting the managers too heavily involved. This again supports the discussion of the factor Top management support and involvement.

\section{V.CONCLUSION AND LIMITATIONS}

The aim of our study was to gain insight into the research field of CSFs for SCM implementation projects. Research in the field of software implementation projects and their CSFs provides valuable information that can enhance the degree to which an organization's implementation project succeeds [15]. As a first step, we carried out a systematic literature review to identify CSFs for SCM projects. Our review turned up only a small number of papers focusing on SCM system implementations - we could only identify 13 relevant papers in this research field. From these papers, we derived 22 different CSFs. However, compared to the CSF literature for ERP system projects (a separate literature review yielded 320 papers dealing with 31 different CSFs for ERP projects), this can be seen as a clear lack of research.

Here, to gain a deeper insight into this field, we set up an empirical study with a specific focus on SCM system implementations. We conducted several interviews within large-scale enterprises which have implemented SCM systems and with consultants who have several years of SCM project experience. Using a guideline consisting of more than 30 initial questions about CSFs, we conducted twelve interviews. We found that all 22 factors identified in the literature review were mentioned by at least one interviewee. Additionally, we were able to identify six additional factors during the interviews. Therefore, there are 28 factors which somehow affect the success of SCM system projects. However, contrary to the rankings resulting from an earlier literature review for ERP projects (see [17] and [21]), we identified factors with a more technological focus as being important for SCM projects. Here, the factors Data migration / data accuracy and SCM system tests are two out of the top three CSFs for SCM implementations. Hence, factors with an organizational characteristic could also be identified as part of the top 5 factors in our interview study (Change management, Available resources, Top management support and involvement, and SCM system acceptance / resistance).

Regarding research question 1 (Q1), we were able to clearly identify 28 factors that have an influence on SCM system implementations. However, we could also show that the importance of the factors for SCM projects differs from the CSFs' ranking for ERP projects (Q2). The implementing companies as well as the SCM system manufacturers have to be aware of these differences in the factors' characteristics, also focusing on technological aspects of the SCM system implementations rather than focusing mainly/only on the organizational factors.

A few limitations of our study must be mentioned as well. For our literature review, we are aware that we cannot be certain that we have identified all relevant papers published in journals and conferences since we made a specific selection of only five databases and four international conferences. Therefore, journals that are not included in our selected databases and the proceedings from other conferences might also provide relevant articles. Another limitation is the coding and ranking of the CSFs. We tried to reduce any subjectivity by formulating coding rules and ranking rules and by discussing the coding of the CSFs with several independent researchers. However, other researchers may code and assess the CSFs in different ways. For the interview study, the interviews conducted and data evaluated represent only an investigation of sample SCM projects in German enterprises. These results are limited to the specifics of these companies and the particular experiences of the consultants. In light of this, we will conduct further case studies and some larger surveys to broaden the results of this investigation.

\section{REFERENCES}

[1] T. H. Davenport, Mission critical: Realizing the promise of enterprise systems. Boston, USA: Harvard Business School Press, 2000, DOI: $10.1225 / 9067$

[2] S. V. Grabski, and S.A. Leech, "Complementary controls and ERP implementation success," International Journal of Accounting Information Systems, vol. 8, no. 1, pp. 17-39, 2007, DOI: 10.1016/j.accinf.2006.12.002.

[3] S. C. L. Koh, and M. Simpson, "Change and uncertainty in SME manufacturing environments using ERP," Journal of Manufacturing Technology Management, vol. 16, no. 6, pp. 629-653, 2005, DOI: $10.1108 / 17410380510609483$

[4] T. M. Somers, and K. Nelson, "The impact of critical success factors across the stages of enterprise resource planning implementations," in Proceedings of the 34th Hawaii International Conference on System Sciences (HICSS 2001), Hawaii, USA, 2001, DOI: 10.1109/HICSS.2001.927129.

[5] A. Busch and W. Dangelmaier, "Integriertes Supply Chain Management - ein koordinationsorientierter Überblick," in Integriertes Supply Chain Management / Theorie und Praxis effektiver unternehmensübergreifender Geschäftsprozesse, 2nd ed., A. Busch and W. Dangelmaier, Eds., Wiesbaden, Germany: Gabler publishing, 2004, pp. 1-24.

[6] H. Bartsch and P. Bickenbach, Supply-Chain-Management mit SAP APO / Supply-Chain-Modelle mit dem Advanced Planner \& Optimizer 3.1, 2nd ed., Bonn, Germany: Galileo Press, 2002.

[7] H. Krcmar, Informationsmanagement, 5th ed., Heidelberg, Germany: Springer, 2001.

[8] G. Mangalaraj, A. Jeyaraj and E. Prater, "Technology Adoption in Supply Chain Management: A Meta-Analysis of Empirical Findings," in Proceedings of the 12th Americas Conference on Information Systems (AMCIS 2006), Acapulco, México, 2006.

[9] M. J. Tarokh and J. Soroor, "Supply Chain Management Information Systems Critical Failure Factors," in Proceedings of the IEEE International Conference on Service Operations and Logistics, and Informatics (SOLI'06), Shanghai, China, 2006, pp. 425-431.

[10] A. Jones, J. Robinson, B. O'Toole, and D. Webb, "Implementing a bespoke supply chain management system to deliver tangible benefits," International Journal of Advanced Manufacturing 
Technology, vol. 30, no. 9/10, pp. 927-937, 2006, DOI: 10.1007/s00170-005-0065-2.

[11] E. W. T. Ngai, T. C. E. Cheng, and S. S. M. Ho, "Critical success factors of web-based supply-chain management systems: An exploratory study," Production Planning \& Control, vol. 15, no 6, pp. 622-630, 2004, DOI: 10.1080/09537280412331283928.

[12] T. Barker, and M. N. Frolick, "ERP Implementation Failure: A Case Study," Information Systems Management, vol. 20 no. 4, pp. 43-49, 2003, DOI: 10.1201/1078/43647.20.4.20030901/ 77292.7.

[13] K. Hsu, J. Sylvestre, and E. N. Sayed, "Avoiding ERP Pitfalls," The Journal of Corporate Accounting \& Finance, vol. 17, no. 4, pp. 67-74, 2006, DOI: 10.1002/jcaf.20217.

[14] P. Achanga, G. Nelde, R. Roy, and E. Shehab, "Critical Success Factors for Lean Implementation within SMEs," Journal of Manufacturing Technology Management, vol. 17, no. 4, pp. 460-471, 2006, DOI: 10.1108/17410380610662889.

[15] S. Finney, and M. Corbett, "ERP Implementation: A Compilation and Analysis of Critical Success Factors," Business Process Management Journal, vol. 13, no. 3, pp. 329-347, 2007, DOI: $10.1108 / 14637150710752272$.

[16] F. F.-H. Nah, K. M. Zuckweiler, and J. L.-S. Lau, "ERP Implementation: Chief Information Officers' Perceptions of Critical Success Factors," International Journal of HumanComputer Interaction, vol. 16, no. 1, pp. 5-22, 2003, DOI: 10.1207/S15327590IJHC1601 2.

[17] C. Leyh, "Critical Success Factors for ERP System Implementation Projects: A Literature Review," in Advances in Enterprise
Information Systems II, C. Møller, and S. Chaudhry, Eds. Leiden, The Netherlands: CRC Press/Balkema, 2012, pp. 45-56.

[18] J. Esteves-Sousa, and J. Pastor-Collado, "Towards the Unification of Critical Success Factors for ERP Implementations," in Proceedings of the 10th Annual Business Information Technology (BIT) Conference, Manchester, UK, 2000.

[19] J. vom Brocke, A. Simons, B. Niehaves, K. Riemer, R. Plattfaut, and A. Cleven, "Reconstructing the Giant: On the Importance of Rigour in Documenting the Literature Search Process," in Proceedings of the 17th European Conference on Information Systems (ECIS 2009), Verona, Italy, 2009.

[20] J. Webster and R. T. Watson, "Analyzing the Past Preparing the Future: Writing a Literature Review," MIS Quarterly, vol. 20, no. 2, pp. xiii-Xxiii, 2002.

[21] C. Leyh, "Which Factors Influence ERP Implementation Projects in Small and Medium-Sized Enterprises?," in Proceedings of the 20th Americas Conference on Information Systems (AMCIS 2014), Savanah, Georgia, USA, 2014.

[22] F. F.-H. Nah, and S. Delgado, "Critical Success Factors for Enterprise Resource Planning Implementation and Upgrade," Journal of Computer Information Systems, vol. 46, no. 29, pp. 99-113, 2006

[23] J. Esteves-Sousa, Definition and Analysis of Critical Success Factors for ERP Implementation Projects. Barcelona, Spain, 2004.

[24] U. Remus, "Critical Success Factors for Implementing Enterprise Portals: A Comparison with ERP Implementations," Business Process Management Journal, vol. 13, no. 4, pp. 538-552, 2007, DOI: $10.1108 / 14637150710763568$ 